\title{
Grand Strategy and Foreign Policy: How Grand Strategy Can Aid Bangladesh's Foreign Policy Rethinking?
}

\author{
Sarwar J. Minar* \\ Senior Officer, International Programs and Relations, Independent University, Bangladesh (IUB) \\ *Corresponding Author Email: sarwar.minar@gmail.com
}

\begin{abstract}
There has been much talk lately about the rethinking of foreign policy of Bangladesh in the post-Cold War 'new world order'. This article argues that formulation of grand strategy can aid to Bangladesh's foreign policy and contribute to the rethinking of Bangladesh's foreign policy. The article investigates the root of misconception about grand strategy and discusses the modern meaning of grand strategy in the $21^{\text {st }}$ century. The article also discusses relations of foreign policy and grand strategy and their place in the statecraft. Through examining secondary literature the article illustrates how grand strategy can aid Bangladesh's foreign policy and can contribute to the rethinking of Bangladesh's foreign policy by giving rationale to Bangladesh's foreign policy, giving better foreign policy direction, helping to prioritize goals of foreign policy, aiding to take cautious foreign policy, cementing consistent foreign policy, seeking long term national goal, undertaking proactive foreign policy and even aiding to shape emerging regional future. The article concludes advocating for further advanced research regarding grand strategy in Bangladesh.
\end{abstract}

\section{Introduction}

There has been much talk lately about rethinking of foreign policy of Bangladesh in the post-Cold War 'new world order'. This paper argues that Grand strategy can aid Bangladesh's foreign policy to a great extent and can contribute in bringing desired rethinking in the foreign policy of Bangladesh. The article, therefore, illustrates how grand strategy can aid Bangladesh's foreign policy. Through examining secondary literature this article argues that Grand strategy can aid Bangladesh's foreign policy rethinking with respect to giving rationale to Bangladesh's foreign policy, giving direction to better foreign policy, prioritizing foreign policy goal, aiding to take cautious foreign policy, cementing consistent foreign policy, seek long term national goal, and even aiding to shape emerging regional future.

The geographical positioning of Bangladesh and the emerging geopolitical matrix of South Asia dictate that Bangladesh should be serious about its foreign policy rethinking. The traditional foreign policy of Bangladesh is limited to only a few areas, some criticize to be only reactive. Though there has been much talk about the rethinking of Bangladesh's foreign policy there has not been any substantial contribution to the rethinking of Bangladesh's foreign policy. Although Bangladesh is celebrating 40 years of independence it has not significantly advanced her International Relations thinking. The 40 years of practicing foreign policy, as Imtiaz Ahmed pointed out to be limited in areas like diplomacy of recognition, economic diplomacy, energy and climate diplomacy etc (Imtiaz, 2011). However this also gives Bangladesh a level of maturity in understanding International Relations which is likely to assist Bangladesh to have a grand strategy. As saying goes that doing great starts from thinking great, Bangladesh should therefore seek to formulate grand strategy for better foreign policy outlook and to play greater role in the construction of future South Asia. 
This paper is divided into five parts. First part deals with perceiving the meaning of foreign policy and grand strategy, tracing the root of misconception of the concept of grand strategy along with the modern meaning of grand strategy in the $21^{\text {st }}$ century. Second part deals with the relation of grand strategy and foreign policy and their place in the statecraft. The third part of the paper illustrates how grand strategy can aid foreign of Bangladesh. Fourth part basically advocates for a 'declared grand strategy' and explains why Bangladesh should have a declared grand strategy. And the fifth part advocates for a locus for grand strategy in the statecraft of Bangladesh, that is where to place the grand strategy. Then the paper concludes presenting an assessment about the barriers and risks of having grand strategy and how these can be minimized or possibly tackled.

\section{Foreign Policy and Grand Strategy: Understanding the Meaning}

While 'Foreign policy' is widely used and very well-known concept throughout the world but grand strategy is not that well known concept and additionally crippled by misconception. Foreign Policy is one of most widely used terms and there is no problem associated with the concept. Any scholarly definition can serve the purpose. In the words of Otto von Bismarck the extension of domestic policy is foreign policy (Halim, 1984). Foreign policy, in sum, refers to the part of state policy that a state pursues to the conduct of relations with other states in order to augment its national interest. However, in terms of grand strategy there is not only lack of understanding but also there is misunderstanding of the concept. Firstly, since the origin of the concept of grand strategy it remained limited to study and practice only handful of states, great powers, of the world and their scholar community. It is, in addition, wrongly perceived that grand strategy is only about war. Writing in 1923, Liddell Hart incorporated the dimension of 'peace' into what was otherwise an essentially military enterprise, noting that while 'the horizon of strategy is bounded by the war, grand strategy looks forward to the subsequent peace' (Baracuhy, 2011). Thus grand strategy, transformed into a larger political design, began to migrate from the realm of pure military studies to the realm of international studies (Baracuhy, 2011). Besides, there are misunderstandings that grand strategy is only about great powers and their primacy, and fighting wars. But the concept of grand strategy has been broadened and developed over time. Grand strategy is not just about great powers and not just about fighting wars.

\section{Deciphering the Root of Misconception}

The root of misconception is rooted in the origin of the concept but not following the subsequent development of the concept. To investigate the root of misconception tracing the origin of grand strategy and perceiving the link between strategy and grand strategy is important. Simple inspection of the definitions offered by Basil Liddell Hart and Colin S Gray is sufficient in this regard. Basil Liddell Hart defined strategy as "the art of distributing and applying military means to fulfill the ends of policy (Art, 1999)." In addition, Liddell Hart suggests that the role of grand strategy-the higher strategy-is to coordinate and direct all the resources of the nation, or the band of nations, towards the attainment of political object of the war - the goal defined by fundamental policy" (Art, 1999). Colin S Gray writes that strategy is the use that is made of force and the threat of force for the ends of policy (Gray, 1999). Colin S Gray additionally noted that strategy at issue may not be military strategy; instead it may be grand strategy that uses 'engagements', meaning all of the relevant instruments of power as threat or in action, for the objectives of statecraft (Gray, 1999). Thus the origin of the idea of grand strategy is rooted in military studies. This is where most scholars draw the line of the concept and the misconception begins about the concept of grand strategy. However, the concept of grand strategy developed further and broadened over time. The misconception can be construed by understanding the modern meaning of grand strategy that developed later on.

\section{The Modern Meaning of Grand Strategy}

The modern meaning of grand strategy is largely contributed by works of Paul M. Kennedy, John Lewis Gaddis, Charles Hill, Michael Howard (Baracuhy, 2011) and Peter Feaver. Paul M. Kennedy defines grand strategy as "the crux of grand strategy lies therefore in policy, that is, in the capacity of the nation's leaders to bring together all of the elements, both military and nonmilitary, for the preservation and enhancement of the nation's long-term (that is, in wartime and peacetime) best interests" (Bassani Jr, 2005). John Lewis Gaddis simply defined 'grand strategy' as the calculated relationship of means to large ends, It's about how one uses whatever one has to get to wherever it is one wants to go (Gaddis, 2009). Peter Feaver pointed that "Grand strategy is a term of art from academia, and refers to the collection of plans and policies that comprise the state's deliberate effort to harness political, military, diplomatic, and economic tools together to advance that state's national interest" (Feaver, 2009). He emphasized grand strategy to be the art of reconciling ends and means. It involves purposive action- what leaders think and want (Feaver, 2009). Former US Senator Gary Hart describes grand strategy as "the application of power and resources to achieve large national purposes" (Bassani Jr, 2005). 
Peter Layton, who is undertaking $\mathrm{PhD}$ on developing grand strategy framework, argued that grand strategy is very distinct from strategy, grand strategy has wider scope, integrative, and forward looking nature, grand strategy aims to shape the world of the future. He further said that grand strategy is more than the application of resources; it involves the development of the resources and their allocation, assembling the man power, money and material necessary to build and sustain the means needed to achieve the goal of grand strategy (Layton, 2012).

\section{Grand Strategy and Foreign Policy in the Statecraft}

It is generally mistakenly assumed that all states can have foreign policy, as they have, but only great powers can have grand strategy, as great powers have historically been having. In addition, some others think 'Foreign policy' and 'Grand strategy' identical, however they are not. It is noteworthy that with the broadened scope of grand strategy all states can have grand strategy no matter where they stand in global power structure as they can have foreign policy. Many consider foreign policy to be core element of statecraft to serve national interest of state. Daryl Copeland considered grand strategy as a core element of statecraft (Granatstein, 2011). Both can help states to pursue and augment states' regional and global interests efficiently.

Conceptually foreign policy is a part of a state's overall national policy which is beyond national jurisdiction and related to the external environment. In the words of Otto von Bismarck the extension of domestic policy is foreign policy (Halim, 1984). Foreign policy, in sum, refers to the policy that a state pursues to the conduct of relations with other states in order to safeguard and augment its national interest. Grand strategy on the other hand refers to the international vision pursued by the foreign policy of a state (Baracuhy, 2011).The scope of grand strategy is essentially broader than the scope of foreign policy. Grand strategy is like 'mother' of foreign policy.

While grand strategy refers to the conceptual framework, foreign policy refers to the political action of the state in international relations. It is possible to conceive grand strategy without foreign policy and foreign policy without grand strategy. The former would mean 'ideas waiting for a prince' and the later would mean 'actions waiting for a Machiavelli'. The latter, however, tends to be disastrous (Baracuhy, 2011). Therefore it is desirable that states have grand strategy for a better and successful foreign policy.

Braz Baracuhy declared that the foreign policy is best conducted and assessed in the light of a grand strategy which incorporates a vision of how a state sees itself in the future, takes into consideration the global balance of power, and defines its positions which serve the national interest. The permanent problem of foreign policy, how to balance multiple objectives and with finite power and resources is incorporated in grand strategy (Baracuhy, 2011).

Grand strategy works like 'mother' of foreign policy. Therefore, not only foreign policy but also grand strategy should be conceived as significant for any statecraft because grand strategy can give better guidance to foreign policy of any state. Grand strategy can contribute to the formulation of consistent and coherent foreign policy over long period. Foreign policy with guidance of grand strategy is sure to benefit the concerned states in formulating better and cautious policies for the state to advance its interests. Grand strategy assists to identify and clearly articulate the interests of state. Additionally, it suggests how to develop, deploy and sustain the necessary means to achieve the goals of national interests. Grand strategy illustrates the rationale for undertaking foreign policy and help to set priorities of foreign policy to seek. Grand strategy dictates what kind of relations to be built with which region of the world and with which state through foreign policy. Grand strategy helps to discern strategic implication for foreign policy choices.

\section{How Grand Strategy Can Aid Bangladesh's Foreign Policy Rethinking?}

Grand strategy can aid Bangladesh's foreign policy rethinking to a great extent. As grand strategic provides basic framework for political action of foreign policy; grand strategy can aid Bangladesh's foreign policy by giving rationale to Bangladesh's foreign policy, giving better foreign policy direction, helping to prioritize goals of foreign policy, aiding to take cautious actions through foreign policy, cementing consistent foreign policy, seeking long term national goal, undertaking proactive foreign policy and even aiding to shape emerging regional future. Each point is elucidated below.

Providing Calculated Rationale for Foreign Policy: Grand strategy can aid by providing rationale to foreign policy of Bangladesh. Grand strategy can aid to identify and clearly articulate national interests and therefore, better serve national interests of Bangladesh. Morgenthau noted that 'national interest' is the driving force of national policy. In the case of Bangladesh national interest embraces such matters as national security, socio-cultural and economic development (Emajuddin, 1984). This can be categorized further. The Primary interest of Bangladesh includes self-preservation, maintaining territorial integrity and political independence. It is claimed that economic development and the achievement of higher level of living are also considered as primary interests of Bangladesh. In addition, trade, aid, access to communication of flows, sources of supply, 
and foreign market are considered as middle range interests of Bangladesh (Emajuddin, 1984). Abdul Halim writing in the 1980s added safeguarding and well as augmenting national power in relation to other states, ideological independence, and maintaining national prestige as national interest of Bangladesh besides previously mentioned interests of Bangladesh (Halim, 1984). Emajuddin Ahamed added, almost in the same time, that preserving peace in regional and international arena is also considered to be interest of Bangladesh. Emajuddin Ahamed noted that desired peace not for the sake of peace but also for the strategic consideration of national development and security (Emajuddin, 1984). However, in the $21^{\text {st }}$ century global politics normative aspect of interest perception has become very important; that is creating and maintaining better image of state is also considered as national interest. In case of Bangladesh, depicting as a responsible member of world community, portraying as strategically important state, portrayal as peace loving state, or expression of willingness to be one of world's garments can be considered as national interest of Bangladesh. These normative aspects of national interest have very significant impact on preserving and advancing the core and middle level interests of Bangladesh. Thus devising grand strategy is apparent to serve not only above mentioned interests of Bangladesh but also project a better image of Bangladesh that she is careful about international relations thinking in the $21^{\text {st }}$ century. Therefore, grand strategy can aid Bangladesh's foreign policy.

Prioritizing Foreign Policy Goals: Grand strategy can help to prioritize aims and goals of Bangladesh. Murdock and Kallmyer pointed that grand strategy is central to establish priorities among a long list of potential objectives (Murdock \& Kallmyer, 2011) to pursue. This prioritization can be divided into two categories. On the one hand, this is to prioritize problems among a list of problems and therefore take appropriate steps to solve the problems for the betterment of Bangladesh. Christopher Hemmer additionally pointed that assessing threats is an essential part of grand strategy; Keeping USA's grand strategy in mind he mentioned that grand strategy can help to prioritize What global regions and issues does Washington need to be deeply concerned about and what ones can be ignored safely? While there is a tendency for a great power's security perimeter to grow, grand strategy is about assessing the most important threats a country needs to put its scarce resources against (Murdock \& Kallmyer, 2011). And on the other hand, this is to prioritize goals and objective among a number or list of goals which to seek first and which one next and therefore to take appropriate steps to pursue. Thus grand strategy can aid in prioritizing foreign policy goals of Bangladesh.

Providing Proper Foreign Policy Direction: Grand strategy can help to reduce ambiguity of real world and help to explaining the world intelligibly and facilitate undertaking consistent action in right time. Grand strategy can thus contribute to set appropriate direction to guide the nation in the right course in times of internal and external turbulence. Grand strategy can assist in giving better direction for Bangladesh's foreign policy. As grand strategy is essentially broader than foreign policy and provide framework and ideas for action, the political leaders of Bangladesh coming into power would get basic guideline and ideas of conducting Bangladesh's foreign policy prudently than they would do otherwise. Simple replication of Braz Baracuhy's declaration would be that the foreign policy of Bangladesh would be best conducted and assessed in the light of a grand strategy which incorporates a vision of how Bangladesh sees itself in the future. Grand strategy additionally would help Bangladesh to take into consideration the global and regional balance of power, and define its positions which serve the national interest of Bangladesh. If grand strategic goal is set to be a responsible actor of global community, or strategically important actor in South Asia, or emerging economic actor, or one of world's garment, successive governments should take proper actions through their foreign policies how to materialize the grand strategic goals efficiently. Grand strategy can thus dictate the successive governments a proper direction for Bangladesh's foreign policy.

Formulating a Proactive Foreign Policy: Many scholars criticize that the foreign policy of Bangladesh to be reactive and advocate strongly that Bangladesh should seek to formulate proactive foreign policy. Bangladesh mostly just reacts to the policies of other states, and the development of regional and global arena. That is mostly because it is not clear what to do and why to do. In a Newsweek article, Fareed Zakaria observed that grand strategy is not 'an abstract concept'. Without a 'broader framework through which to view the world', he stressed, 'any administration will be driven by the news, reacting rather than leading' (Zakaria, 2008) However, formulating a grand strategy would give proper guidance what to do and thus Bangladesh will be able to formulate proactive foreign policy which will be conducive to serving national interest of Bangladesh invariably.

Formulating Cautious Foreign Policy: Grand strategy provides a broad framework that delineates the actors in the system or sub-system, balance of power among the actors. Within such a broader framework it becomes easier to perceive and undertake cautious foreign policy. The guiding framework will obviously help Bangladeshi to perceive why to undertake foreign policy, what kinds of policy to undertake; what to do and what not to do. Thus grand strategy would help to undertake cautious foreign policy of Bangladesh.

Formulating Consistent and Coherent Foreign Policy: Grand strategy can help Bangladesh to coherently pursue her long term goals and interests. Grand strategy would assist in the continuation of foreign policy to prove Bangladesh a responsible member of world community. Grand strategy would assist in the continuation of 
policy how to make the best use of population by sending workers in other countries and for that purpose how to build special relations with specific states of regions like Middle East, East ASIA or South East Asia where Bangladeshi workers to be one of worlds garments irrespective of change of governments. Similarly what steps and tasks to undertake to develop internal capacity, to building relations and make strategic partnerships, and to adopting with immediate and remote external environment ultimately to gradually increase the share of strategic importance of Bangladesh in South Asia and to reach to the grand strategic goal to be a strategically important actor.

Aiding to Develop By-partisan Culture for Foreign Policy: Grand strategy can play a critical role in creating domestic coherence and developing by-partisan culture necessary for a better foreign policy formulation. Grand strategy can help to focus effort by coordinating government agencies which increases the chances of success of effort. Publicly articulated and coherent grand strategy will contribute to bring coherence in other sectors of state policy. Formulating a Grand strategy will contribute to various departments of the government to develop their short, medium and long-term plans in accordance with the overall grand national goal. Grand strategy will assist armed forces to acquire armaments and advance technologies with a focus on a definite national goal. Grand strategy can provide a basis for prioritizing national resource allocations which will also improve coordination among various national agencies and provide a central direction to individual and collective actions. Thus grand strategy can further help Bangladesh's foreign policy.

Aiding to Seek Long Term National Goal: Grand strategy can aid Bangladesh to seek long term goal of national interest.As determining a nation's interest is the central task of grand strategy (Art, 1999) and as grand strategy provides a framework to seek long term goal of a nations, grand strategy can help Bangladesh to seek long term goal of national interest. Additionally, as grand strategy also deals with the providing the means necessary it can help Bangladesh to devise appropriate plan to develop the means necessary to pursue long term goal of national interest of Bangladesh. One of the common problems that Bangladesh faces regarding foreign policy is change of foreign policy with the change of government. This harms preserving national interest of Bangladesh in the long term. Grand strategy thus can aid to seek long-term national interest irrespective of regime change.

Aiding to Shape Regional Future: Grand strategy can help to play constructive role in constructing a better South Asian future. South Asia is emerging as one of the key regions of importance in the Asian cross board. India and China are rising so rapidly, economically and therefore militarily, that has increased South Asia's importance in the world politics as well as concern of the other South Asian states. Besides their sheer economic cooperation they have competing and overlapping interest perception in South Asia. The United States, world's only superpower has already expresses the importance of South Asia and its assured increasing engagement with South Asia in coming decades. The emerging security scenario in South Asia is like to be a complex one mostly because of the simultaneous rise of China and India. Besides, poverty, nuclearization and terrorism, the simultaneous and rapid rise of China and India along with the increased engagement of the United States are the fundamental factors for understanding the twenty-first century South Asian future. There is a formidable possibility of competition among the power actors to strive to establish their authority in South Asia. Hence, formulating a grand strategy may be helpful for Bangladesh to adapt with the emerging complex scenario of South Asian International Relations and to shape the emerging future of South Asia.

To harness the above mentioned benefits Bangladesh should seriously consider formulating grand strategy within such complex emerging South Asian order. Formulation of grand strategy can aid immensely Bangladesh's foreign policy rethinking and serve to safeguard and augment national interest of Bangladesh in short term, middle term and in the long term.

\section{Why should Bangladesh have a 'Declared Grand Strategy'?}

This paper argues that Bangladesh should have a 'Declared Grand Strategy'. Some experts showed their reluctance to talk about Bangladesh to have 'grand strategy' expressing that this might stimulate suspicion in India, China especially in Myanmar. ${ }^{1}$ Some Indians suspect that a strong Sino-Bangladesh relation could disrupt Indian interest in this region. For instance Indian scholars like Anand Kumar expressed his suspicion about transit to China and Chinese assistance to highway building from Chittagong to Kunming and deep sea port developing in Chittagong port (Uddin \& Bhuiyan, 2011). Vijay Sakhuja argued that Bangladesh is an important factor in China's political-military calculus which gives China additional leverage to check Indian force (Uddin \& Bhuiyan, 2011). Urvashi Aneja also advocated for reducing the suspicion of India and Bangladesh (Aneja, 2006). But reversely this paper argues that a declared grand strategy, with clearly stated strategic objective of Bangladesh, will reduce suspicion of both India and China about Bangladesh's intention and strategic vision which will play a role in preserving regional stability. In addition, South Asia has not yet created any situation

\footnotetext{
${ }^{1}$ Dr Delwar Hossain, a professor of the Department of International Relations, Dhaka University was interviewed on April 3, 2012.
} 
like cold war, "if you are not with us than you are against us" (Imtiaz, 2011), or which was repeated in the post 9/11 situation, "with us or against us" by W. Bush declared in 2001 and this makes it more acceptable that Bangladesh should have a declared grand strategy. Additionally, some vaguely argue that the tension rose from the rise of India and China with ultimately end up with an understanding of maintaining own 'sphere of influence' in the region. Now if Bangladesh formulates and maintains a declared such a grand strategy that she supports and acts to preserve regional stability may encourage the both to do so consciously and actively which will ultimately contribute to the maintenance of peace and stability in the region.

\section{Where to Place Grand Strategy in the Statecraft of Bangladesh?}

Bangladesh is a transitional democracy and there are many problems in the statecraft of Bangladesh. It is well recognized that the practice of democracy in Bangladesh is a 'two-party democracy' where one party between the two dominant parties comes into power in almost a 'cyclic order'. The new government that comes into power changes the policies of prior government.

In such kind of scenario where to place the grand strategy to get an effective result remains a big question. Hence the example set by Indonesia can be followed. One of the three key foreign policy bases of Indonesia is 'broad foreign policy principles'; The framework is made must for every government of Indonesia to follow while every government is allowed to define priority within this framework (Anwar \& Crouch, 2003). That is, this grand strategy should be placed at such a place where every government of Bangladesh will remain bound to follow the broad framework set by grand strategy while they will enjoy the freedom to have their priorities. As grand strategy gives a broader framework and environment to formulate foreign policy in a better way (Baracuhy, 2011), this will surely help Bangladesh to formulate and direct its foreign policies in a better way.

\section{An Assessment of Barriers and Risks}

Formulating grand strategy can enormously aid to the rethinking of Bangladesh's foreign policy. However, there are risks and barriers in grand strategy formulation. Krishnappa Venkatshamy shortly discusses the barriers and risks of grand strategy (Venkatshamy, 2012) while writing about India's grand strategy. However the barriers and risks of grand strategy formulation are discussed below each following possible response to counter barriers and risks.

Krishnappa Venkatshamy pointed that 'lack of conceptual clarity' to be a barrier to the formulation of grand strategy as the concept means different thing to different thinkers. He further saw problem in the process formulating grand strategy as barrier because there is possibility of ontological bias, predilection of only certain stakeholders who formulate grand strategy. The quality of vision and leadership can deteriorate formulating grand strategy, mentioned Krishnappa Venkatshamy. He suspects that as grand strategy is formulated through political process which is due to uncertain strategic environment, competing goals, varied perceptions about reality, and scarcity of resources makes it impossible to formulate, let alone implement, optimal strategies. In such scenario specific group tend to suit their particular interests which will aggravate grand strategy formulation. In addition, viewing reality too simply and paradigm problem, what explains what is permissible, possible and legitimate, may dominate leaders' understanding of their identity that guide their behavior can also be barrier to formulate grand strategy.

It is firstly necessary to understand that though there are barriers countering the barriers and formulating a good grand strategy can assist to safeguard and augment national interest of Bangladesh. While there is ambiguity of definition this also opens the avenue of defining, clarifying and contextualizing the concept as necessary; just need to undertake sufficient research. Inclusion of various research institutions, think tanks and their expertise besides governmental expertise can contribute to overcome the possible biases of reflection of particular groups' view. Competition over scare resource and willingness to suit one groups' interest is actually a perennial problem in almost any realm which is very hard to control let alone eliminate. Therefore any attempt of minimizing such possibility would be wise, consciousness of policy makers and transparent decision making can help to overcome the problem. Paradigm's influence in real but people need to understand paradigms are useful tools for appreciation of reality, but are not reality itself. Influence of history can also influence negatively. The simply perceived means-end chain can even be tricky and harmonizing them can create further barrier. Therefore more carefulness can lead to diminish and overcome the barriers. Total dedication of the grand strategy architects is also crucial; any slightest reluctance can create big barriers to the formulation of grand strategy. Bangladesh has to be prudent to come over these barriers to formulate an appropriate grand strategy. The current level Bangladesh has, can help enough to formulate grand strategy and if above mentioned steps can be taken that would be even better.

There risks of grand strategy are not negligible either. The risks associated with formulation of grand strategy are needed to take into consideration seriously. As wrong strategy can lead to defeat in the war, grand strategy can therefore be disastrous. As stability of environment determines opportunities and risks, 
predetermined framework can be self-contradictorily risky and certain predetermined prescription can prove to be ineffective in certain turbulent situations. Therefore au courant information should seriously be taken into consideration. While promoting focused effort, there is risk of creating contradiction among various groups. Therefore careful supervision is needed to counter the risk. Any possibility of creating and increasing division among people needs to tackle cautiously. While providing with consistency there is risk that desperate elements can create inconsistency. The tasks of identify creation and national consensus building also runs the risk of causing further divisions. Therefore proper and cautious steps are very essential to take against the possible risks and such steps can surely contribute to the formulation of a better and effective grand strategy for Bangladesh. Civil society organization, Think tanks, various research organizations should come forward and play key role from their part in devising grand strategy for Bangladesh.

When barriers and risks are more or less known it is likely to be helpful to the formulation of a better grand strategy keeping risks and barriers in mind. Therefore careful consideration of risks and barriers and countering measures are likely to be helpful in formulating better grand strategy for Bangladesh.

\section{Discussion and Conclusion}

The abovementioned descant illustrates that grand strategy can extraordinarily aid Bangladesh's foreign policy rethinking which is extensively expected in the scenario of the $21^{\text {st }}$ century global politics. This is the most favorable time for Bangladesh to formulate a grand strategy to formulate and undertake an integrated, comprehensive and long term plan for Bangladesh. With very limited means and capabilities Bangladesh should look for developing a broad framework to augment national interest by taking cautious, efficient and coherent policy. Grand strategy can aid to efficient, cautious, coherent foreign policy making of Bangladesh. Since the independence of Bangladesh, the scope of foreign policy remains very limited. Except for diplomacy for recognition of independence, seeking to establish SAARC, and seeking for foreign aids and grants the foreign policy of Bangladesh remains merely reactive. In the post-Cold War global politics all the states, especially small states, have been urged for rethinking respective foreign policy. As many have already argued that Bangladesh should seriously consider rethinking Bangladesh's foreign policy, a grand strategy can serve the ambition of rethinking foreign policy of Bangladesh. Additionally, with the simultaneous rise of India and China and their increasing engagement with South Asia signifies the emergence of a complicated South Asian future where possibility of strife remains high. In such scenario Bangladesh should look forward to play a constructive role in construction of a better South Asian future; a grand strategy can aid in Bangladesh's playing such constructive role in constructing a better South Asia future.

In addition, a coherent and cautious grand strategic framework can aid developing essential skills and resources of Bangladesh as necessary means to reach to the desired goal of grand strategy. Additionally, grand strategy can help to elucidate ambiguities and uncertainties of emerging future as well as to avail the opportunity for serving the national interest of Bangladesh. Bangladesh can thus play a constructive role in constructing a better image, a better state and constructing a better South Asian future. Grand strategy this can provide a guiding framework for the long term achievable enduring national interest of Bangladesh with reference to sustainable means to achieve that can be materialized through cautious actions taken by foreign policy of Bangladesh.

The formulating and implementation of grand strategy is not without risks and barriers. The success of grand strategy formulation depends on political and economic viability. The future of Bangladesh depends on developing grand strategic framework and setting a long term vision for Bangladesh. The execution of grand strategy is very difficult but not impossible. As formulation of grand strategy is crucial for a better future of Bangladesh and South Asia, further research about grand strategy is very essential. The leading universities of Bangladesh, especially those teach International Relations can start offering course on grand strategy, arrange seminars and can start researching on grand strategy which will ultimately help in better grand strategy development for Bangladesh. Prominent think tanks of Bangladesh can initiate program to research and develop better grand strategy for Bangladesh.

\section{Conflict of interest}

The authors declare no conflict of interest.

\section{References}

Aneja, U. (2006). China-Bangladesh relations: An emerging strategic partnership. IPCS Special Report, 33(3).

Anwar, D. F., \& Crouch, H. A. (2003). Indonesia: foreign policy and domestic politics. Institute of Southeast Asian Studies. 
Art, R. J. (1999). Geopolitics updated: The strategy of selective engagement. International Security, 23(3), 79113.

Baracuhy, B. (2011). The Art of Grand Strategy. Review of Grand Strategies: Literature, Statecraft, and World Order by Charles Hill, Survival, 53(1), 147-152.

Bassani Jr, J. A. (2005). Saving the World for Democracy. An historical analysis of America's grand strategy in the 21st Century. National Defense Univ Norfolk Va Joint Advanced Warfighting School.

Emajuddin, A. (1984). Bangladesh and the Policy of Peace and Non-alignment. in EmajuddinAhamed (ed.) Foreign Policy of Bangladesh: A Small State's Imperative, Dhaka, UPL.

Feaver, P. (2009). What is grand strategy and why do we need it. Foreign Policy, 8.

Gaddis, J. L. (2009). What is Grand Strategy? the keynote address for a conference on "American Grand Strategy after War," sponsored by the Triangle Institute for Security Studies and the Duke University Program in American Grand Strategy.

Granatstein, J. L. (2011). Can Canada have a grand strategy?. In Grand Strategy Symposium, Canadian Forces College, Toronto, 6-7.

Gray, C. S. (1999). Modern strategy (Vol. 42). Oxford: Oxford University Press.

Halim, M. A. (1984). Foreign Policy of Bangladesh: Framework for Analysis. in Emajuddin Ahmed (ed.) Foreign Policy of Bangladesh: A Small State's Imperative. Dhaka: UPL.

Imtiaz. A. (2011). Bangladesh Foreign Policy: Constraints, Compulsions and Choices. BIISS Journal, 32(3).

Layton, P. (2012). The idea of grand strategy. The RUSI journal, 157(4), 56-61.

Murdock, C., \& Kallmyer, K. (2011). Applied grand strategy: making tough choices in an era of limits and constraint. Orbis, 55(4), 541-557.

Uddin, M. J., \& Bhuiyan, M. R. (2011). Sino-Bangladesh Relations: Appraisal. BIISS Journal, 32(1).

Venkatshamy, K. (2012). The Problem of Grand Strategy", Journal of Defense Studies, 6(3).

Zakaria, F. (2008). Wanted: A new grand strategy. Newsweek. 